\title{
FOUND FOOTAGE HORROR
}

\section{FOUND FOOTAGE HORROR}

\author{
Itxaso DEL CASTILLO AIRA \\ Universidad del País Vasco / EuskalHerrikoUnibertsitatea \\ mirenitxaso.castillo@ehu.eus
}

Resumen: El Found Footage Horror (falsos documentales de ciencia ficción y terror) es un subgénero muy prolífico y con gran éxito de público desde 2007. Este artículo estudia tres rasgos distintivos del Found Footage: la inclusión de la cámara en la narración, la limitación del campo, y la mala calidad de la imagen. Para ello, se centra en el análisis de Chronicle (Josh Trank, 2012) y el primer capítulo de V/H/S (2012), el dirigido por David Bruckner "Amateur Night".

Palabras clave: Found Footage. Terror. Amateur. Vigilancia. Háptico. Chronicle. Josh Trank. V/H/S. David Bruckner.

Abstract: Found Footage Horror is a prolific and succesfull subgenre sin 2007. This article focusses on three distinctive traits of Found Footage Horror: inclusion of the camera into the narrative, limitation of the field of vision, and bad quality of the image. For this purpose, it analyzes Chronicle (Josh Trank, 2012) and the first chapter of $V / H / S$ (2012), directed by David Bruckner "Amateur Night".

Key Words: Found Footage. Horror. Amateur. Surveillance. Haptic. Chronicle. Josh Trank. V/H/S. David Bruckner. 


\section{INTRODUCCIÓN}

Como aquella advertencia que prologaba las novelas góticas asegurando que lo que teníamos entre las manos eran manuscritos hallados o legados por una persona desaparecida en misteriosas circunstancias, en la última década han proliferado películas de género que también quieren hacernos creer que lo que vemos es real, que alguien lo grabó sin saber que no podría contarlo. Me estoy refiriendo a lo que aquí se denomina Falso Documental de Terror y/o Fantástico, pero que los anglosajones llaman Found Footage Horror, en su traducción, metraje encontrado de terror. Este término puede llevar a confusión, ya que, originalmente, el Found Footage o metraje encontrado son aquellas películas construidas a partir de otras, ya sean películas domésticas que hallan en mercadillos o incluso en la basura (los documentales de Alan Berliner) o remontan a una existente (Woody Allen con What's Up, Tiger Lily?).

Sin embargo, dentro del género de terror y fantástico, se usa para denominar aquellas historias sobrenaturales de ficción grabadas por algún personaje de la trama con cámara en mano, webcams, móvil y/o circuitos cerrados de seguridad u otras cámaras de vigilancia. En ningún caso existe una cámara "invisible", propia del cine tradicional, sino que siempre se justifica el origen de la imagen. David Bordwell acuña el término "metraje descubierto", ya que las historias casi siempre comienzan con una advertencia sobre el hallazgo de ese material, así como el desvanecimiento de sus autores.

Aunque no sea quizá el más riguroso, usaré el término Found Footage Horror, tanto para películas de miedo como para las de ciencia ficción, por ser el que los aficionados del género manejan. La película que inauguró este subgénero fue El proyecto de la bruja de Blair (Daniel Myrick, Eduardo Sánchez, 1999), una película independiente de bajo presupuesto, en la que un grupo de estudiantes se adentran en el bosque para grabar un documental sobre la leyenda de una bruja, y nunca más se supo de ellos. El éxito de la cinta fue arrollador, pero la proliferación masiva de películas, muchas de ellas mainstream, se sucede a partir de 2007. Su éxito más rotundo fue Paranormal Activity (Oren Peli, 2007), que se convertirá en una saga de 4 partes y que lleva recaudados 700 millones de dólares en todo el mundo. Desde entonces, se estrenan unas 5 películas de media al año de estas características.

Mi objetivo es analizar 3 rasgos distintivos del Found Footage: la inclusión de la cámara en la narración, la limitación del campo, y la mala calidad de la imagen. Estas características van más allá de formal, son de carácter semántico. Para ello, me centro en una serie de fragmentos de esta dos películas, una de terror y otra de género fantástico: uno de los capítulos de V/H/S (varios autores, 2012) y Chronicle (Josh Trank, 2012).

$\mathrm{V} / \mathrm{H} / \mathrm{S}$ trata de un grupo de vándalos que una noche entran a una casa y hallan un cadáver en una sala de visionado de cintas de vídeo. Cada cinta es una historia terrorífica 
y sangrienta. Me centraré en el primer capítulo, "Amateur Night" (David Bruckner), que cuenta cómo tres jóvenes salen de marcha con intención de ligar y grabar el encuentro sexual con unas gafas-cámara que uno lleva puestas. Chronicle, en cambio, cuenta la historia de tres jóvenes que encuentran un meteorito y adquieren superpoderes.

\section{LA INCLUSIÓN DE LA CÁMARA EN LA NARRACIÓN}

Ambas películas, como todas las Found Footage, son grabadas por los protagonistas de la historia con medios de aficionado. De hecho, en "Amateur Night", la cámara está en unas falsas gafas que se apagan y se encienden, grabando a trompicones. A pesar de que quizás, debido a su mala calidad sonora y visual, además de un montaje que no busca una transición invisible, sino que manifiesta su brusquedad, estas películas transmiten una sensación de inmediatez, de veracidad y ausencia de manipulación; un documento obtenido mediante la observación, sin injerencias. Resulta paradójico que cuanto más se muestra la artificialidad del proceso cinematográfico, cuanto más se pone en evidencia lo que el audiovisual tiene de construcción, más sensación de realismo transmite. Incluso cuando el contenido que nos muestra es de carácter paranormal.

Es importante señalar que la aceptación y expansión de esta estética en el cine de terror está ligado a la aparición de YouTube en 2005, tal y como mantiene Alexandra Heller-Nicolas. La difusión de contenido generado por el usuario ha llegado hasta los mismos informativos de TV: aceptamos bajos niveles de calidad en aras de su validez como documento o testimonio. Lo mismo ocurre con las imágenes de vigilancia. El atraco de un establecimiento registrado por su cámara de seguridad se divulga, aunque apenas se distingan unos bultos, porque estimamos que es la imagen más real que existe, porque no puede engañar. Tal y como plantea Sebastian Lefait, en "Surveillance on Screen", la hegemonía del ojo humano ha sido reemplazada por la del ojo mecánico. Hemos pasado de un cine en el que la cámara creaba un lugar invisible para el espectador, a "un espectador que mira lo que otro observa e interpreta lo observado dentro de un nuevo criterio de realismo científico; aquel en el que la lente de la cámara es más real que el ojo humano" (Lefait, 2012: 8). De alguna manera, la cámara es mejor, más fiable que una persona.

En Chronicle la cámara tiene entidad de personaje, cuya relación con el protagonista va más allá de la de un mero instrumento. La relación evoluciona a medida que lo hace el personaje, contribuyendo a reforzar la evolución de su arco dramático. La película cuenta la siguiente historia. Andrew, el protagonista, es un adolescente cuya madre se está muriendo y el padre es un alcohólico que lo maltrata. Compra una cámara para "grabarlo todo", porque le gusta tener "una barrera entre el mundo y él". Gracias a ella descubre el meteorito que lo convierte en superhéroe junto a otros dos chicos, y, lo más importante, 
descubre la amistad. Pero la muerte de uno de ellos, y finalmente la de la madre, hace que Andrew entre en una espiral de destrucción que solo acaba con su muerte en manos de su único y último amigo.

He realizado este pequeño montaje en el que se ven las tres fases de la relación entre Andrew y la cámara: la videograbadora comienza siendo un personaje pero acaba convirtiéndose en el verdadero Andrew, encarnándolo. El poder y las prótesis visuales van de la mano.

Al comienzo de la película. Se escucha el sonido de una cremallera y la voz de un hombre furioso, pero hasta que no se enciende la cámara no vemos nada. Esos primeros segundos son los únicos en los que la cámara diegética o, mejor dicho, el sonido diegético y el extradiegético no coinciden. A partir de ahora el director realiza virguerías para que siempre esté justificado el origen de la imagen.

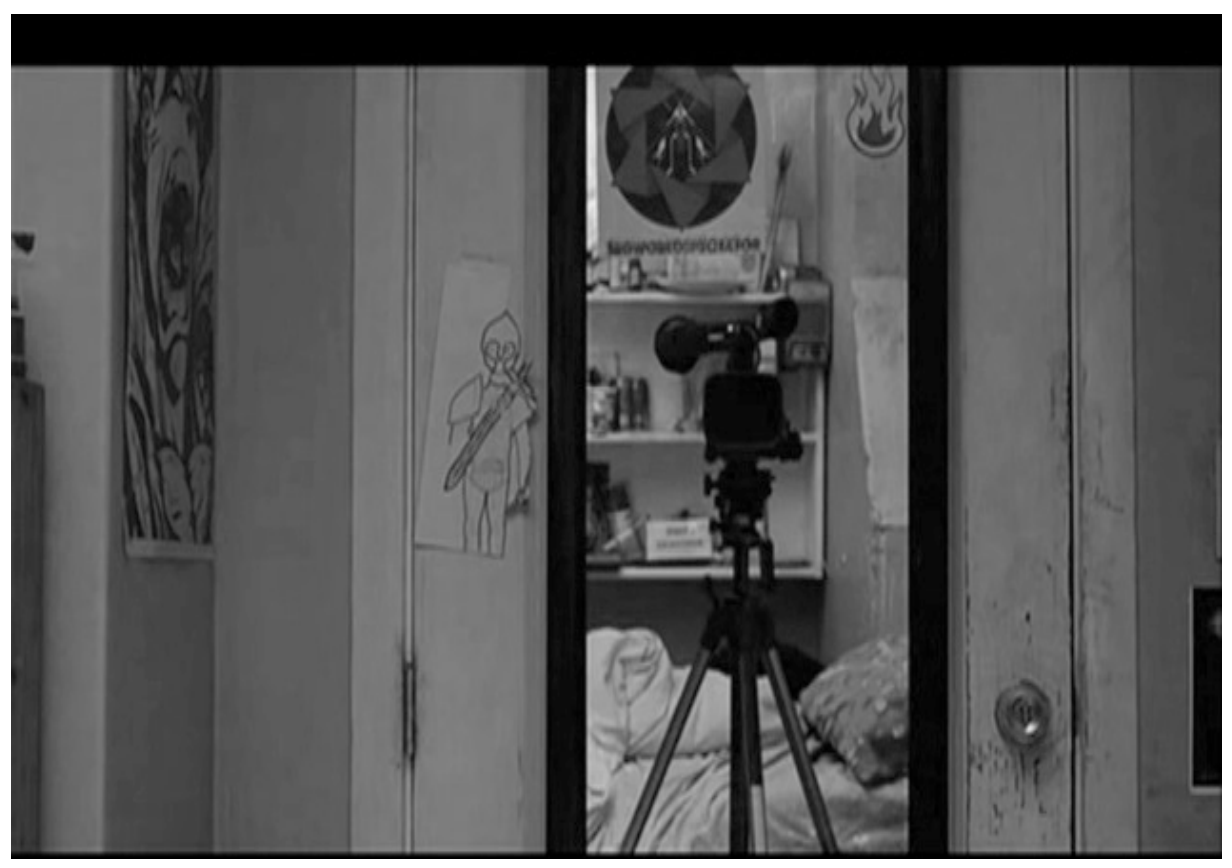

La cámara se alza en el centro de la imagen. Es presentada como un personaje, como un arma que apunta. El padre golpea la puerta para entrar pero Andrew no le deja porque está borracho. Le desafía con su cámara, tal y como dice, “me compré una cámara y voy a grabar todo a partir de ahora", y el padre se marcha. Se asocia cámara con poder. A medida que Andrew sea más poderoso, mejor manejará su cámara hasta dominarlas a todas.

En la batalla final, Andrew se alza como un villano destructor e invoca a todas las cámaras, como acólitos de su amo. Él es la cámara suprema. 


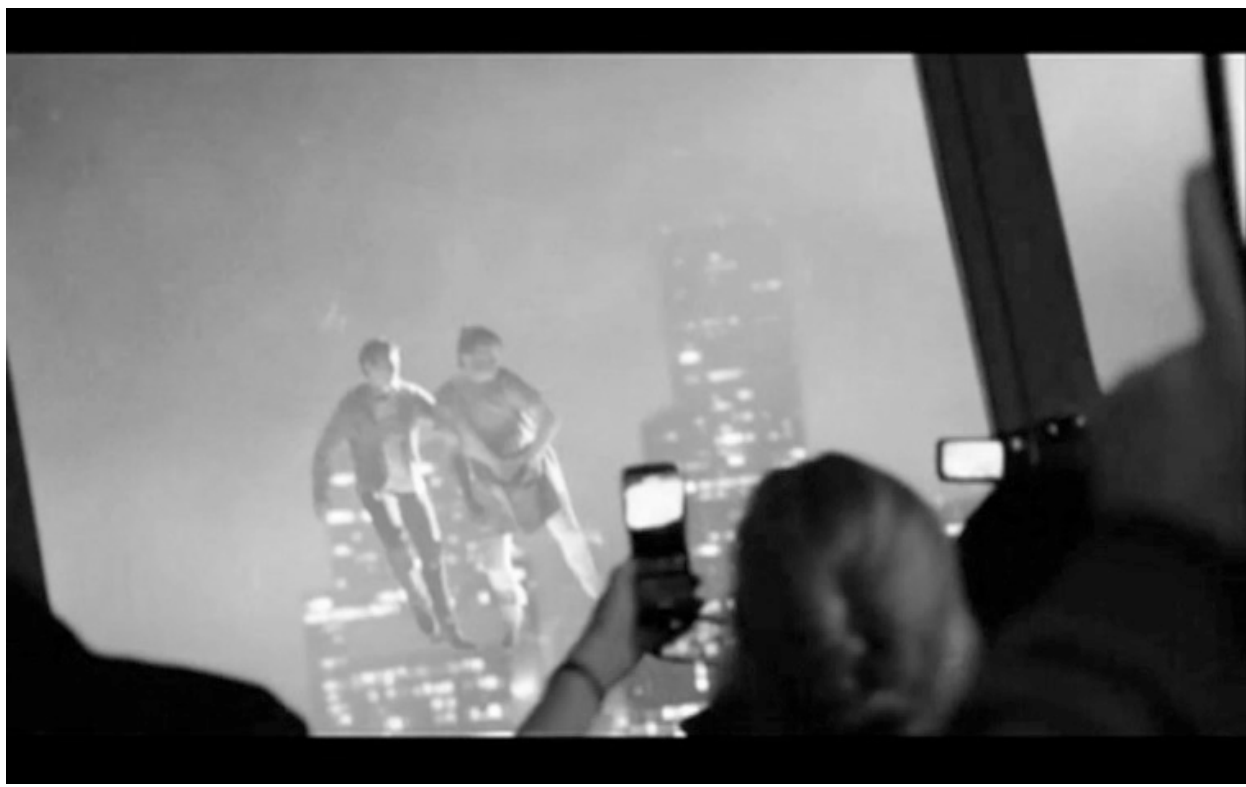

También, de algún modo, es la cámara social, ya que ha pasado de la soledad de su dormitorio donde se cuestiona la autoimagen frente a un padre autoritario, a las miles de cámara que se vigilan mutuamente. Los ojos del mundo observan atónitos su poder infinito.

La secuencia de la pelea refleja fielmente lo que Hille Koske la ha denominado "the cam era", una era de representaciones infinitas, de una omnipresencia de cámaras , ya sean de vigilancia o no, que provocan la sensación de que todo puede ser registrado. El mundo es sustancial de ser filmado, nada queda excluido.

"La vigilancia ubicua y permanente", mantiene Sebastien Lefait (2012: 16), "trae la experiencia cinematográfica a la vida cotidiana, provocando desplazamientos frecuentes en la frontera entre lo real y lo ficción. El mundo del cine se define por esta frontera y esta nueva cultura de ver y ser visto, creado por el auge de la vigilancia, también moldea la forma en la que están hechas las películas".

Steve se despide de Andrew hablando a la cámara, convertida en él. La deja en el Tibet, lugar que Andrew siempre quiso visitar. La relación que mantiene Andrew con su cámara desde el principio de la película, que saca lo mejor de sí mismo, que le protege del dolor del mundo, que le transforma en alguna medida, nos hace preguntarnos cómo nos relacionamos todos culturalmente con las nuevas tecnologías en la sociedad de las pantallas. Existen nuevos dispositivos audiovisuales que, indudablemente, están modificando la forma de representar la realidad y también a nosotros mismos. 


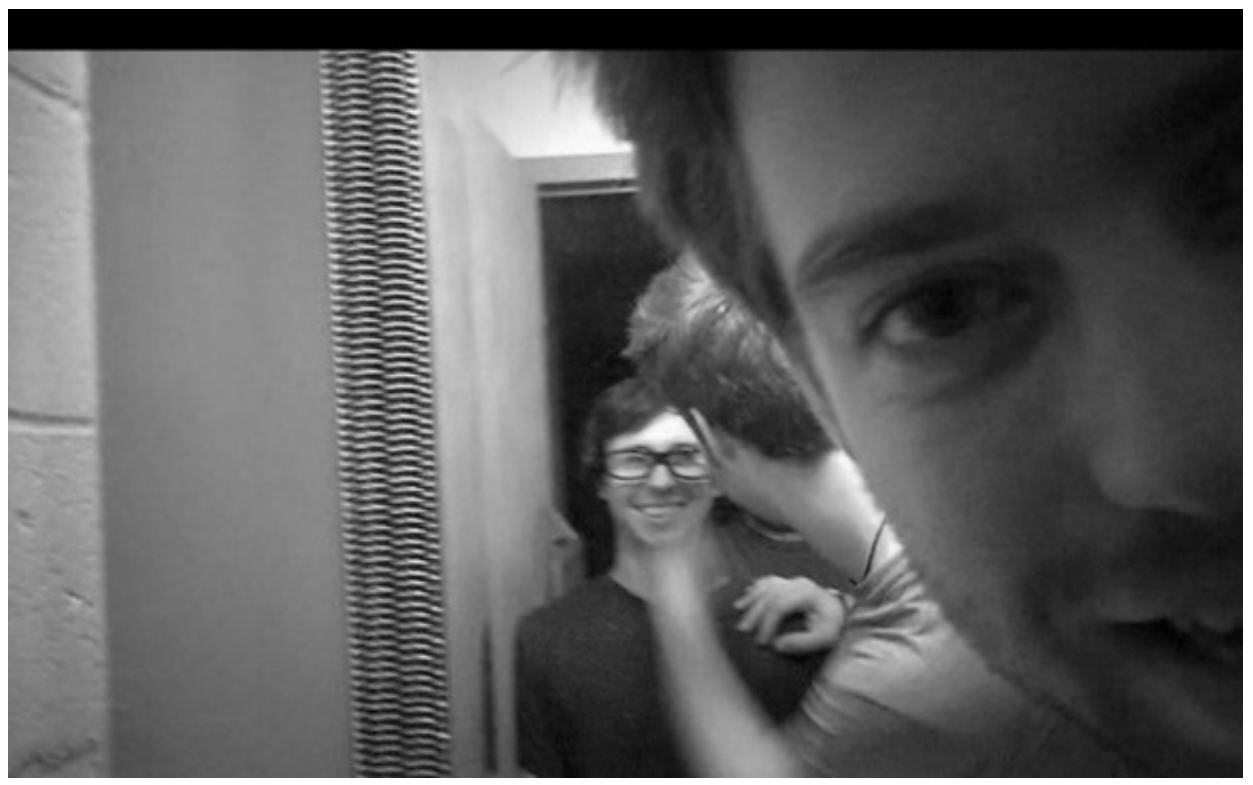

Tal y como decía Jean-Louis Comolli, "La variación histórica de las técnicas cinematográficas, su aparición, desaparición, sus fases de convergencia, sus periodos de dominación y declive creo que no dependen de un orden racional lineal de mejora tecnológica ni un ejemplo de progreso científico autónomo, sino más bien en compensaciones, ajustes, arreglos realizados por la configuración social para representarse a sí misma, esto es, entenderse a sí misma, identificarse así misma y producirse así misma en sus representaciones" (Lefait, 2012: 16).

\section{LA LIMITACIÓN DE CAMPO}

Por otro lado, debemos preguntarnos cómo es la mirada de esa cámara autorreferencial del subgénero que nos ocupa. La mayor parte del tiempo narra con un punto de vista subjetivo, por lo que no posee la ubicuidad necesaria para verlo todo, es decir, se restringe mucha información. Este hecho acentúa la fuerza que el fuera de campo tiene en el cine de terror, con sus sonidos, presencia s e irrupciones sorpresivas. Todo lo que la cámara no nos muestra, lo rellenamos nosotros con nuestros miedos.

Esta limitación de campo rompe la convención de la mirada total, omnipresente, del cine tradicional. Laura Mulvey definió esa mirada como masculina, una mirada agresiva que sexualizaba los cuerpos femeninos a través de la cámara voyeurística. Siguiendo esta lógica, podemos pensar que la mirada limitada, fragmentada, característica del Found Footage Horror anula o reduce esa agresividad masculina, siendo una estética más 
adecuada para narrativas que cuestionan la división de géneros tradicional. Así tiene lugar en el primer capítulo de $\mathrm{V} / \mathrm{H} / \mathrm{S}$.

"Amateur Night", cuenta cómo Clint lleva unas gafas-cámara que graba todo lo que él ve. Sus amigos quieren ligar con una chica y grabar el encuentro sexual. A pesar de sus reticencias, Clint acaba accediendo.

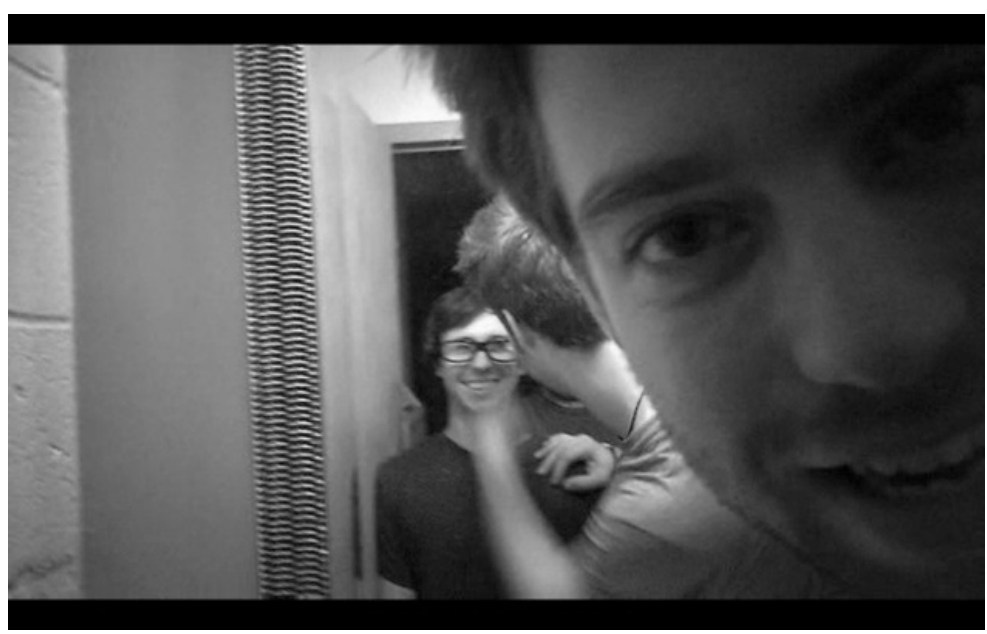

En un bar, mientras sus amigos ligan, Clint es abordado por una joven que le lleva mirando fijamente toda la noche. La visión que proporciona la cámara es confusa, en movimiento, centrada en la acción que esté realizando en ese momento (coger el vaso, beber...), sin que podamos ver la escena en su conjunto con claridad: es una mirada parcelada, limitada. En contraste, la mirada de ella es directa, serena. Interpela a la cámara, mirándonos fijamente. Ella posee la mirada, ella es la poderosa.

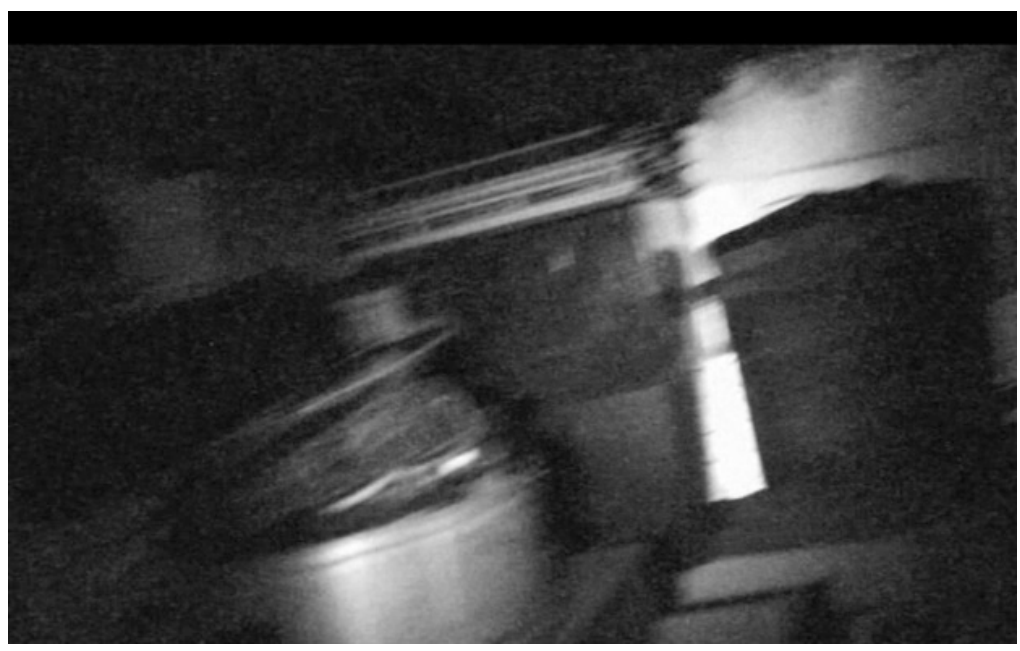


A medida que vemos que los amigos de Clint son unos machistas y unos cretinos, la misteriosa chica no se despega de ellos. Ha confesado su amor por Clint, aunque este no ha sabido cómo reaccionar a esto. En la habitación del hotel, cuando el abuso sexual de la joven comienza, ella se transforma en un demonio y sus dos compinches son devorados, y acaban con los genitales literalmente seccionados. Clint, objeto de deseo de la súcubo, es secuestrado y llevado por los aires, sin que se vuelva saber de él.

La limitación de la cámara contribuye, en este caso, a problematizar las categorías de género de la historia. La trama de regador regado es aquí la del depredador sexual depredado; el hombre que lleva una cámara equivalente a su mirada (la mirada masculina del cine tradicional) ya no es poderosa como lo fue antaño, sino parcial y limitada, por lo que termina siendo un objeto sexual ante los ojos de una agresiva figura femenina.

\section{LA MALA CALIDAD DE IMAGEN}

Otro rasgo de la mirada de la cámara autorreferencial del Found Footage Horror es su mala calidad de definición. El pixel se nota, hay interferencias, poca iluminación, muchos de los objetos aparecen muy cerca y se fija en el detalle poroso. Es una mirada háptica, que invoca al sentido del tacto. Este tipo de imagen "pone énfasis en la inclinación del espectador en contemplarlas. (...) Es una mirada que se mueve en la superficie plana de la pantalla por algún tiempo antes de que el espectador se dé cuenta de lo que está observando" (Marks, 2000: 162-163). Laura Marks es quien acuñó este término, y diferencia entre visualidad háptica y óptica: mientras la percepción óptica privilegia el poder representacional de la imagen, la percepción háptica privilegia la presencia material de la imagen. La imagen háptica fuerza al espectador a contemplar la imagen en sí misma, en vez de ser impelido por la narrativa. La falta de nitidez de las películas de Found Footage Horror fuerzan al espectador a buscar en la imagen, a disfrutar de la textura de la imagen.

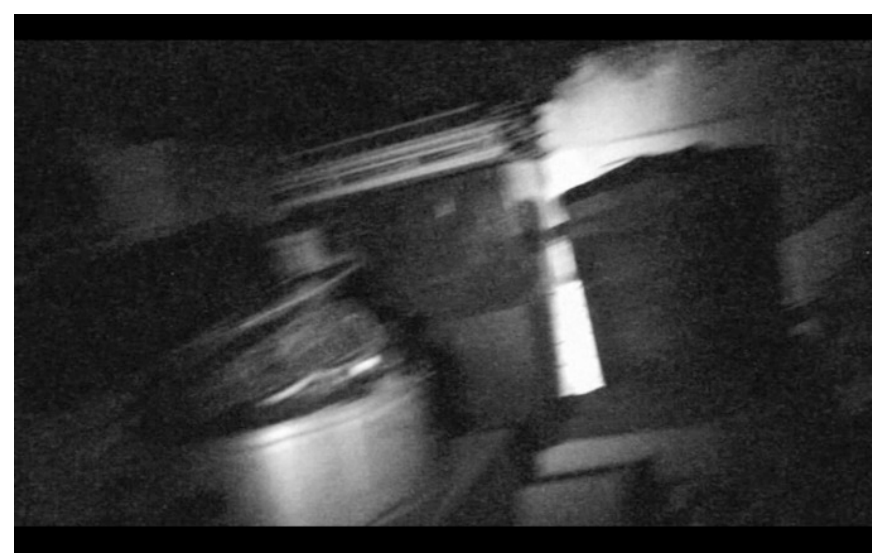


En $\mathrm{V} / \mathrm{H} / \mathrm{S}$, la textura y calidad de la imagen recrea a la de una cinta VHS usada. A pesar de ser una película de 2012, nos hace creer que está grabada en ese formato, aunque luego las historias que se ven en las cintas son actuales, incluso alguna trata sobre webcams. Este anacronismo, además de ser un guiño a los aficionados del género que se pasaban cintas, está relacionado con la búsqueda de esta imagen háptica.

Proveniente de otras formas de experiencia sensorial, primariamente el tacto y la kinestesia, la visualidad háptica incluye al cuerpo más que lo hace la visualidad óptica. El tacto es un sentido localizado en la superficie del cuerpo: considerar al cine como háptico es solo un paso a considerar las maneras en que el cine apela al cuerpo como un todo.

Angela Ndalianis aplica este concepto en el cine de terror y concluye que "esta relación corporal está más marcada en el cuerpo cinematográfico (el mundo audiovisual ficcional que nos presentan) y refleja y amplifica la experiencia de lo horrible, sufriente y volátil de los cuerpos dentro de la historia narrativa" (Ndalianis, 2012: 23).

El Found Footage Horror es un género que, según Brigid Cherry, trata "sobre la forma en la que la tecnología influye en la manera de ver". Confío en que este artículo haya podido desvelar algunas de sus claves.

\section{REFERENCIAS BIBLIOGRÁFICAS}

HELLER-NICHOLAS, Alexandra (2014). Found Footage Horror Films. Fear and the appearance of reality. Jefferson: McFarland.

KOSKELA, Hille (2003). “Cam Era-The Contemporary urban panopticon". Surveillance and Society 1(3), 292-313.

LEFAIT, Sebastian (2012). Surveillance on Screen: Monitoring contemporary films and television programs. Lanham, MD: Scarecrow Press.

MARKS, Laura (2000). Skin of the Film. Intercultural Cinema, embodiment and the senses. Durham and London: Duke University Press.

MULVEY, Laura (1975). “Visual Pleasure and Narrative Cinema”. Screen 16.3, 6-18.

NDALIANIS, Angela (2012). The horror sensorium. Media and the Senses. Jefferson: McFarland. 
